\title{
Perspectives and Opportunities for Precompetitive Public-Private Partnerships in the Biomedical Sector
}

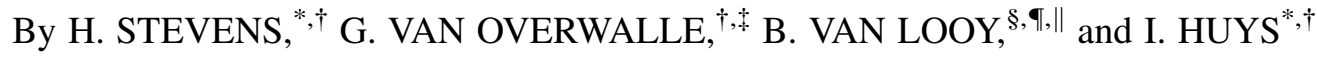

$\mathrm{B}$ IOPHARMACEUTICAL ENTERPRISES face major challenges: increased competition, falling R\&D budgets, increasing regulatory hurdles, accelerating technological complexity, future patent cliffs, and declining numbers of promising projects in their drug pipelines. $^{1-3}$ With closure of research laboratories and redirection of $R \& D$ expenditures, pharmaceutical firms are changing their strategic direction. ${ }^{4}$

Basic knowledge of underlying disease mechanisms seems required to accelerate the development of the next-generation's drugs. Interdisciplinary, translational research for drug development requires collaboration between stakeholders from industry and academia. ${ }^{5,6}$ A shared objective is to translate basic biological research into therapies serving patients. ${ }^{7}$ Industry realizes the potential of combining different ideas, skills, and expertise in technologically demanding areas and is increasingly tapping into early-phase research conducted at universities and small- and medium-sized enterprises specializing in biotechnology (biotech SMEs). ${ }^{8}$ In addition, sharing knowledge with competitors at the precompetitive-and even at a competitive - stage is increasingly considered to be both relevant and viable. ${ }^{9}$

*Department of Pharmaceutical \& Pharmacological Sciences, Research Centre for Pharmaceutical Care and Pharmacoeconomics O\&N II, Leuven, Belgium. Corresponding author: Hilde Stevens Herestraat 49, Box 521, 3000 Leuven, Belgium; E-mail: hilde.stevens@pharm.kuleuven.be

Centre for Intellectual Property Rights, Faculty of Law, University of Leuven, Leuven, Belgium.

†ilburg Institute for Law, Technology and Society (TILT), Tilburg University, Tilburg, The Netherlands.

${ }^{\S}$ Department of Managerial Economics, Strategy and Innovation (MSI), Faculty of Business and Economics, University of Leuven, Leuven, Belgium.

${ }^{\top}$ Centre for Research \& Development Monitoring (ECOOM), Belgium.

"Institute for Innovation and Governance Studies (IGS), University of Twente, Enschede, The Netherlands.
Traditionally, the pharmaceutical business model relies heavily on intellectual property (IP) rights, ${ }^{10}$ especially patents. Pharmaceutical companies and industry observers are questioning whether traditional business models adequately respond to the current crisis in the drug development sector, and whether alternative business models are needed to revive productivity in the sector. ${ }^{11,12}$

Straightforward collaborative models, such as outsourcing and bilateral contracts, have a proven track record in the pharmaceutical sector. ${ }^{4,7}$ Currently, alternative and more complex collaboration models are being explored. ${ }^{4,9,13}$ The number of multi-partner consortia in the health sector, often based on a

\footnotetext{
${ }^{1}$ Scudellari M. Clinical drive prompts pharma and academia to partner up. Nat Med 2011;17:3.

${ }^{2}$ Wagner JA. Open-minded to open innovation and precompetitive collaboration. Clin Pharmacol Ther 2010;87:511-515.

${ }^{3}$ Widdus R. Public-private partnerships: an overview. Trans R Soc Trop Med Hyg 2005;99(Suppl 1):S1-S8.

${ }^{4}$ Lenford H. Drug buddies. Nature 2011;474:433-443 [cited June 23, 2011].

${ }^{5}$ Munos BH, Chin WW. A call for sharing: adapting pharmaceutical research to new realities. Sci Transl Med 2009;1(9): $9 \mathrm{~cm} 8$.

${ }^{6}$ Munos BH. Can open-source drug R\&D repower pharmaceutical innovation? Clin Pharmacol Ther 2010;87:534-536.

${ }^{7}$ Melese T, Lin SM, Chang JL, Cohen NH. Open innovation networks between academia and industry: an imperative for breakthrough therapies. Nat Med 2009;15:502-507.

${ }^{8}$ Kling J. Biotechs follow big pharma lead back into academia. Nature Biotechnol 2011;29:555-556.

${ }^{9}$ Mullard A. Partnering between pharma peers on the rise. Nature Rev 2011;10:561-562.

${ }^{10}$ Gold ER, Bubela T, Carbone J, Gagnon MA, Srulovicz T, Joly Y. At the intersection of health and intellectual property: issues, tools and directions for Health Canada. 30-3-2010. The Innovation Partnership (TIP).

${ }^{11}$ Williams RS, Desmond-Hellman S. Making translation work. Science 2011;332:1359.

${ }^{12}$ Woodcock J. Precompetitive research: a new prescription for drug development? Clin Pharmacol Ther 2010;87:521-523.

${ }^{13}$ Mullard A. Could pharma open its drugs freezers? Nature Reviews 2011;10:399-400.
} 
public-private partnership (PPP) model, ${ }^{14,15}$ is increasing, addressing research, public education, advocacy, and regulation, as well as quality and standardization. ${ }^{16-18}$

The first PPP in life sciences dated from the late 1980s: the Merck Mectizan ${ }^{\circledR}$ Donation Program. ${ }^{3,19}$ With this initiative, a trend was initiated for PPPs at the precompetitive stage (Table 1). ${ }^{7,20}$ Precompetitive PPPs traditionally focus on research activities situated before the actual drug development process. These PPPs aim to solve basic research questions and to generate technology platforms, research tools, and predictive models to advance knowledge about disease pathways. $^{3,15,20-23}$ Such activities precede the market exploitation phase and offer opportunities to reduce throughput time and risks associated with such predevelopment phases. The precompetitive R\&D PPP model is still in its infancy. Hence, there is still much to learn about its design and implementation. Knowledge development through sharing is enhanced in precompetitive partnerships. Taking into account the multifaceted partnering model of (precompetitive) PPPs and the heterogeneity of partners-including their often conflicting missions, objectives, and cultures-it is not surprising that IP rights play a pivotal role and that IP and trust issues are part of the negotiation process. $^{6,13,22,24-27}$ In life sciences projects, different types of IP protection can be sought, depending on the intellectual creation. The most common IP protection for inventions is patents, but also other forms of IP protection are used, such as trademark protection, industrial design, copyright, sui generis database rights, plant variety rights, or protection of undisclosed information (trade secrets). Patents are awarded for inventions satisfying the criteria of novelty, inventiveness, and industrial application. They award the inventor a right to exclude others from using his invention for a certain period of time in a certain territory.

The motives for participation in a precompetitive PPP found in the literature differ ${ }^{18}$ : whereas academia and public sector institutions primarily perform fundamental research, the role of industry is focused on clinical development of candidate products. Whereas academic researchers are focused on publishing results, industry tries to generate return on investment and increase profits. ${ }^{7,28}$ Whereas academia participates in precompetitive PPPs in return for research funding, ${ }^{4}$ the life sciences industry participates in strategic partnerships with academia to gain additional insights and knowledge in the first phases of the drug development lifecycle: the pre-discovery and drug discovery phase. ${ }^{7}$ The interest from industry in biotechnology SMEs' high-quality assets has increased for the same reasons. ${ }^{29,30}$ Image building or political reasons can also provide motives for participation.

Although the literature emphasizes differences, it remains relatively silent on whether these differenceswithin the framework of PPPs-enable complementary roles or might imply conflicts (of interest) as well.
The present empirical study explores the motivations of different stakeholder groups for participation in precompetitive biopharmaceutical R\&D PPPs. Fundamental questions arise, such as: what are the motives to participate in a (precompetitive) R\&D PPP? To what extent are motives coinciding, conflicting or complementary? What are the challenges and barriers to overcome? The answers provide insight into the expectations of different stakeholders and what might be needed to improve collaboration. By interviewing different stakeholder groups, the role of IP for the participation in PPPs, as experienced by the stakeholders, can be defined.

\section{CONCEPTS}

\section{Public-Private Partnerships (PPPs)}

A variety of definitions for PPPs exists. ${ }^{21,31}$ For the purpose of this study, PPPs are defined as

${ }^{14}$ Gallagher WM, Tweats D, Koenig J. Omic profiling for drug safety assessment: current trends and public-private partnerships. Drug Discov Today 2009;14:337-342.

${ }^{15}$ Croft SL. Public-private partnership: from there to here. Trans R Soc Trop Med Hyg 2005;99(Suppl 1):S9-S14.

${ }^{16}$ Demotes-Mainard J, Canet E, Segard L. Public-private partnership models in France and in Europe. Therapie 2006;61:325-323.

${ }^{17}$ European PPP Expertise Centre (EPEC). Market Update.

Review of the European PPP Market in 2010. 2011.

${ }^{18}$ Reich MR. Public-private partnerships for public health. Nat Med 2000;6:617-620.

${ }^{19}$ Ridley RG. Putting the partnership into public-private partnerships. Bull World Health Org 2001;79:694.

${ }^{20}$ Wagner JA, Prince M, Wright EC. The Biomarkers Consortium: practice and pitfalls of open-source precompetitive collaboration. Clin Pharmacol Ther 2010;87:539-542.

${ }^{21}$ Widdus R. Public-private partnerships for health: their main targets, their diversity, and their future directions. Bull World Health Organ 2001;79:713-720.

${ }^{22}$ Goldman M. Reflections on the Innovative Medicines Initiative. Nat Rev 2011;10:321-322.

${ }^{23}$ Cain C. Making the case for precompetitive clinical development. Science-Business eXchange 2011;4(20).

${ }^{24}$ Expanding precompetitive space. Nat Rev Drug Discovery 2011;10:883.

${ }^{25}$ Cressey D. Traditional drug-discovery model ripe for reform. Nature 2011;471:17-18

${ }^{26}$ Napa J. Open source drug discovery: a feasible business model? Pharma Focus Asia 2011.

${ }^{27}$ Vargas G, Boutouyrie B, Ostrowitzki S, Santarelli L. Arguments against precompetitive collaboration. Clin Pharmacol Ther 2010;87:527-529.

${ }^{28}$ Moran N. New models emerge for commercializing university assets. Nat Biotechnol 2011;29:774-775.

${ }^{29}$ Borshell N. Is deal-making becoming more difficult? Nat Rev 2011;10:404.

${ }^{30}$ Opar A. Bridging the drug-diagnostic divide. Nat Rev 2011;10:323-324.

${ }^{31}$ Richter J. Public-private partnerships for health: a trend with no alternatives? Development 2004;47(2):43-48. 
collaborative models based on a contractual agreement between (a) at least one not-for-profit organization and (b) at least one for-profit organization. ${ }^{18}$ The former may be public-sector institutions, such as (inter)governmental agencies or civil society bodies (e.g., nongovernmental organizations and academia); the latter include life science (such as pharmaceutical and biotechnology) companies, which may be SMEs. ${ }^{3,32}$ The concept has evolved over time, and today, PPPs can also include partners from the community sector, voluntary sector, and other (health) groups receiving funding from private and public sources. ${ }^{33,34}$ These groups are often initiated by (inter)governmental agencies to achieve a shared objective- the public interest-in a cost-efficient manner ${ }^{24,32}$ by combining multiple skills, expertise, and financial resources. ${ }^{34}$

Public-private partnerships do not equal joint ventures or research investments between one public and one private partner. The term "partnership" implies joint decision-making between a number of entities, whereby the different parties jointly address issues with respect to resources, accountability, transparency, and conflicts of interest. ${ }^{3,32}$

\section{Different Types and Characteristics of PPPs}

Depending on the mission and the objectives, we classified (bio)pharmaceutical R\&D PPPs into different types (Table 1).

Precompetitive PPPs have emerged quite recently (Table 1) and are focused on optimizing the knowledge generation phase or the pre-discovery stage in the drug development lifecycle (Fig. 1), ${ }^{3}$ although some have led to the identification of potential drug compounds. Such PPPs attempt to answer fundamental research questions. They are aimed at generating technology platforms, research tools, shared databases, and predictive models to advance knowledge of diseases, as well as to enhance development of safer and more effective drugs. ${ }^{12}$ The primary goal is not to discover or develop products or therapies, so there is no use of particular candidate products as starting materials. ${ }^{3}$ In contrast to most product development PPPs and product access PPPs (defined further on), which often focus on diseases in commercially unattractive target populations, ${ }^{21}$ precompetitive PPPs are directed toward a broad range of topics identified as future priorities for health. ${ }^{22,35}$ Such PPPs, having the potential to address broader population needs in the developed world, are therefore more attractive for investment. Governments look favorably on competitors joining forces in a precompetitive phase. ${ }^{2,27}$ Initiatives such as the Innovative Medicines Initiative (IMI) and Critical Path Institute (C-Path) establish PPPs between different stakeholders in a "precompetitive" field (Fig. 1).

Proof-of-Concept PPPs (POC PPPs) aim to test the proof-of-concept of promising molecules for new medicines (Fig. 1). These partnerships start after drug discovery and lead research projects on target identification, target validation, and assay development, screening hit identification, optimization of a lead compound, preclinical (in vivo animal) studies, and (sometimes) early clinical studies (Phase IIa) to establish first-in-human evidence.

Product Development PPPs (PD PPPs) are based on a "portfolio approach," whereby compounds are tested, and successful candidate products are developed in a parallel way. Spreading the investment in drug development over several projects, whereby a project with low expected outcome can be quickly abandoned, which is instrumental for handling the risk of failure effectively. ${ }^{15,36}$ In the past, small-scale PD PPPs focusing on neglected infectious diseases often failed because of lack of funding, expertise, and committed involvement of companies. ${ }^{19}$ To date, having a track record of almost 20 years, this class of PPPs is generally recognized for its successes, such as the Medicines for Malaria Venture (MMV), which achieved its primary mission of bringing antimalaria formulations to the market. ${ }^{3,15,36}$

Product Access PPPs (PA PPPs), based on drug donation, discounting, and distribution by large pharmaceutical companies, are the oldest PPPs in the life sciences (Table 1). ${ }^{3,21}$ These partnerships can be established to increase access to a variety of medicines, such as the Global Alliance for Vaccines and Immunization (GAVI), which provides vaccines in the poorest countries. ${ }^{37}$ They can also be directed toward specific diseases, such as Merck's Mectizan ${ }^{\circledR}$ Donation Program for the worldwide control of onchocerciasis, also known as river blindness, which is the world's second most common infectious cause of blindness. ${ }^{3,19}$

\section{INTERVIEW RESULTS}

\section{Motives Pro Participation: Different But Complementary}

At the time of interviewing, a major theme in the establishment of - and participation in-precompetitive

\footnotetext{
${ }^{32}$ Widdus R. Public-private partnerships for health require thoughtful evaluation. Bull World Health Org 2003;81:235.

${ }^{33}$ Yescombe ER. Public-private partnerships: principles of policy and finance. Butterworth-Heinemann (Elsevier), 2011.

${ }^{34}$ Geddes M. Making public private partnerships work: building relationships and understanding cultures. Gower Publishing Limited, 2005.

${ }^{35}$ Treaty on European Union (EU), 7 February 1992. O.J. (C191) 1, 31 I.L.M. 253. 7-2-1992.

${ }^{36}$ Nwaka S. Drug discovery and beyond: the role of publicprivate partnerships in improving access to new malaria medicines. Trans R Soc Trop Med Hyg 2011;99S:S20-S29.

${ }^{37}$ Martin JF, Marshall J. New tendencies and strategies in international immunisation: GAVI and The Vaccine Fund. Vaccine 2003;21:587-592
} 
Table 1. Categorization of PPPs

\begin{tabular}{|c|c|c|c|c|c|c|}
\hline \multirow[b]{2}{*}{ Name of PPP } & & \multicolumn{4}{|c|}{ Category by Principal Aim } & \multirow[b]{2}{*}{$\begin{array}{l}\text { Start } \\
\text { Date }\end{array}$} \\
\hline & & $\begin{array}{l}\text { PreC } \\
\text { PPP }\end{array}$ & $\begin{array}{l}P O C \\
P P P\end{array}$ & $\begin{array}{l}P D \\
P P P\end{array}$ & $\begin{array}{c}P A \\
P P P\end{array}$ & \\
\hline $\begin{array}{l}\text { Mectizan }^{\circledR} \text { Donation } \\
\text { Program }\end{array}$ & & & & & $\mathrm{x}$ & 1987 \\
\hline IAVI & International AIDS Vaccine Initiatives & $(\mathrm{x})$ & $\mathrm{x}$ & $\mathrm{x}$ & & 1996 \\
\hline $\begin{array}{l}\text { Mectizan }^{\circledR} \text { and } \\
\text { albendazole }\end{array}$ & & & & & $\mathrm{x}$ & 1998 \\
\hline MMV & Medicines for Malaria Venture & $(\mathrm{x})$ & $\mathrm{x}$ & $\mathrm{x}$ & $\mathrm{x}$ & 1999 \\
\hline GAELF & $\begin{array}{l}\text { Global Alliance to Eliminate } \\
\text { Lymphatic Filariasis }\end{array}$ & & & & $\mathrm{x}$ & 2000 \\
\hline GAVI/VF & $\begin{array}{l}\text { Global Alliance for Vaccines and } \\
\text { Immunization }\end{array}$ & & & & $\mathrm{x}$ & 2000 \\
\hline IOWH & Institute for OneWorld Health & & $\mathrm{x}$ & $\mathrm{x}$ & & 2000 \\
\hline TB Alliance/GATB & $\begin{array}{l}\text { Global Alliance for TB Drug } \\
\text { Development }\end{array}$ & $(\mathrm{x})$ & $\mathrm{x}$ & $\mathrm{x}$ & & 2000 \\
\hline OAI & Osteoarthritis Initiative & $\mathrm{x}$ & & & & 2001 \\
\hline IPM & $\begin{array}{l}\text { International Partnership for } \\
\text { Microbicides }\end{array}$ & & $\mathrm{x}$ & $\mathrm{x}$ & $\mathrm{x}$ & 2002 \\
\hline $\begin{array}{l}\text { Japanese Toxicogenomics } \\
\text { Project }\end{array}$ & & $\mathrm{x}$ & & & & 2002 \\
\hline $\begin{array}{l}\text { Aeras Global TB } \\
\text { Vaccine Foundation }\end{array}$ & & $(\mathrm{x})$ & $\mathrm{x}$ & $\mathrm{x}$ & & 2003 \\
\hline DNDi & Drugs for Neglected Diseases Initiative & $(\mathrm{x})$ & $\mathrm{x}$ & $\mathrm{x}$ & $(\mathrm{x})$ & 2003 \\
\hline GCGH & Grand Challenges in Global Health & $\mathrm{x}$ & $\mathrm{x}$ & $\mathrm{x}$ & & 2003 \\
\hline TRC & RNAi Consortium & $\mathrm{x}$ & $\mathrm{x}$ & & & 2003 \\
\hline ADNI & $\begin{array}{l}\text { Alzheimer's Disease Neuroimaging } \\
\text { Initiative }\end{array}$ & $\mathrm{x}$ & & & & 2004 \\
\hline DGI & Diabetes Genetics Initiative & $\mathrm{x}$ & (x) & & & 2004 \\
\hline SGC & Structural Genomics Consortium & $\mathrm{x}$ & & & & 2004 \\
\hline TDI & Tropical Diseases Initiative & $\mathrm{x}$ & & & & 2004 \\
\hline C-Path & Critical Path Institute & $\mathrm{x}$ & & & & 2005 \\
\hline BioWin & Biotechnologies Wallonie Innovation & $\mathrm{x}$ & & & & 2006 \\
\hline CAVD & $\begin{array}{l}\text { Collaboration for AIDS Vaccine } \\
\text { Discovery }\end{array}$ & $\mathrm{x}$ & $\mathrm{x}$ & $\mathrm{x}$ & & 2006 \\
\hline CD3 & Centre for Drug Design and Discovery & & $\mathrm{x}$ & & & 2006 \\
\hline CDRD & $\begin{array}{l}\text { Centre for Drugs Research and } \\
\text { Development }\end{array}$ & & $\mathrm{x}$ & & & 2006 \\
\hline $\begin{array}{l}\text { FDA Public-Private } \\
\text { Partnership Program }\end{array}$ & & $\mathrm{x}$ & & & & 2006 \\
\hline GAIN & $\begin{array}{l}\text { Genetic Association Identification } \\
\text { Network }\end{array}$ & $\mathrm{x}$ & & & & 2006 \\
\hline TI Pharma & Top Institute Pharma & $\mathrm{x}$ & $\mathrm{x}$ & $\mathrm{x}$ & & 2006 \\
\hline BMM & BioMedical Materials Program & $\mathrm{x}$ & & & & 2007 \\
\hline CTMM (Diagnostics) & $\begin{array}{l}\text { Center for Translational Molecular } \\
\text { Medicine }\end{array}$ & $\mathrm{x}$ & $\mathrm{x}$ & $\mathrm{x}$ & & 2007 \\
\hline Project PPPs Under FP-Health & European Framework Programmes & $\mathrm{x}$ & & & & 2007 \\
\hline ITC & International Transporter Consortium & $\mathrm{x}$ & & & & 2007 \\
\hline OMOP & $\begin{array}{l}\text { Observational Medical Outcomes } \\
\text { Partnership }\end{array}$ & $\mathrm{x}$ & & & & 2007 \\
\hline SysDiag & & $\mathrm{x}$ & & & & 2007 \\
\hline IMI & Innovative Medicines Initiative & $\mathrm{x}$ & $(\mathrm{x})$ & & & 2008 \\
\hline OSDD & Open Source Drug Discovery & $\mathrm{x}$ & $\mathrm{x}$ & $\mathrm{x}$ & & 2008 \\
\hline Eurobiomed & & $\mathrm{x}$ & $\mathrm{x}$ & $\mathrm{x}$ & & 2009 \\
\hline LDC & Lead Discovery Center & & $\mathrm{x}$ & & & 2009 \\
\hline Sage Bionetworks & Sage Bionetworks Commons & $\mathrm{x}$ & & & & 2009 \\
\hline
\end{tabular}

Non-exhaustive list to illustrate the emergence of precompetitive PPPs in the life science R\&D sector. Examples are filtered through literature review (Sources: Pubmed, ScienceDirect, Google, and cited references). Based on a review of the websites, categorization was done. 


\begin{tabular}{|c|ccc|}
\hline $\begin{array}{c}\text { Pre-Discovery } \\
\text { Upstream Research }\end{array}$ & Drug Discovery & $\begin{array}{c}\text { Drug Development } \\
\text { Clinical } \\
\text { (Phase I, II, III) }\end{array}$ & $\begin{array}{c}\text { Post-Approval } \\
\text { (Phase IV) }\end{array}$ \\
\hline
\end{tabular}

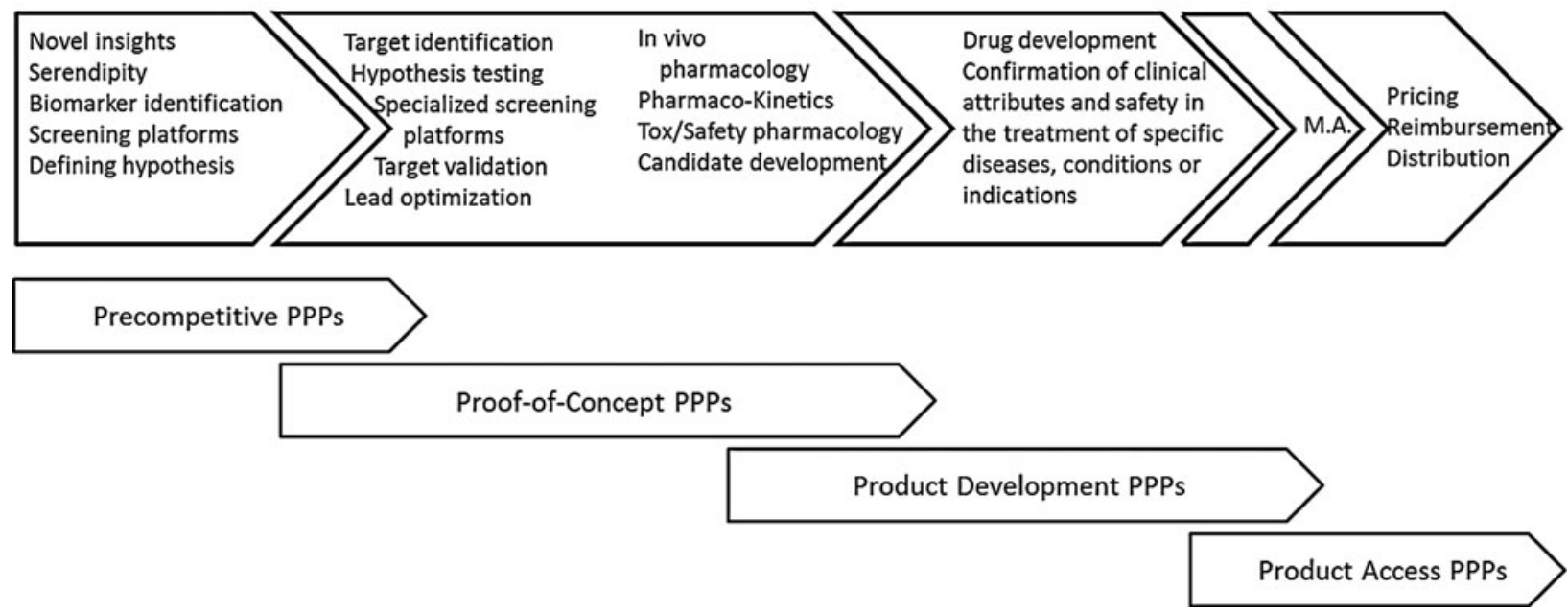

FIG. 1. On the discovery-development-delivery continuum in the biopharmaceutical sector, precompetitive PPPs are situated before and at the early discovery of promising drug compounds. Proof-of-concept PPPs (POC PPPs) aim at target identification and validation. Product development PPPs (PD PPPs) focus on drug development. Product access PPPs (PA PPPs) target drug donation, discounting, and distribution. (M.A. = market authorization)

PPPs concerned the motivations of public and private actors. Common motives for the biomedical industry, SMEs, TTOs, and academia to participate in precompetitive PPPs were "innovation" and "enhancement of expertise in a specific field." Pharmaceutical company experts highlighted "creativity," "risk sharing," "cost reduction," and "avoiding duplication" as important drivers to participate. A major factor for academia and TTOs was research funding: all seven academic and all five TTO interviewees indicated that "money" was one of the main motives for participation, as well as "project scope" and "publication possibilities." SMEs hoped to see their participation in PPPs converted into "money" and "knowledge transfer." An intriguing result was the interest of SMEs in "IP opportunities."

It is important to note that both industry and academia added "complementarity of knowledge and disciplines" and "generating information on (possible) future partners" to the list of motives for participation in a PPP. All the interviewees stated that "networking possibilities" and "top scientists participating in the project" were important considerations for participation. Some interviewees highlighted the "fear of missing out." Participation in a PPP was seen to be good for an institution's or company's image and for the researchers' status, according to academic interviewees. SMEs and TTOs stressed the importance of "the possibility to partner with a well-established company." Most interviewees highly welcomed the participation of a European agency, such as the European Medicines
Agency (EMA), in PPPs for guidance and early involvement in regulatory approaches for innovative ideas.

\section{Motives Contra Participation: Handling IP}

During the interviews, "lack of trust" was indicated as a common reason impeding interviewees' participation in a PPP. While "IP opportunities" were not rated high as a driver for participation, "IP hurdles," "secrecy issues," and "fear of giving away know-how" were major concerns of all stakeholders. Interviewees with experience in participating in PPPs also added "the administrative burden" and "PPPs' organizational structure" as jeopardizing future participation. Pharmaceutical companies and TTOs further stated that "high cost" and "lack of innovation" could also explain non-participation. Academic, TTO, and industry interviewees acknowledged the difficult position for SMEs, and the limited return on investment they might expect.

\section{Intellectual Property Issues in PPPs}

Remarkably, SMEs listed "IP opportunities" as a motive for participation. At the same time, SMEs as well as TTOs considered IP a hurdle for participation in a PPP. All five TTO interviewees stated that a PPP's IP framework could hinder participation. "Lack of trust" was highly ranked by all interviewees and was related to IP hurdles. Some academic interviewees were convinced that industry tries to protect its 
intellectual assets with IP, but expects academia to share all its IP, considering it to be "common," "precompetitive" knowledge.

Academia/TTO and SMEs highlighted their concerns with regard to "publication versus patent filing" and "loss of exclusivity." The lack of "access to background" (background IP means pre-existing IP made available to the partners of the consortium prior to the commencement of the project) or, conversely, "access to background" that reaches too far, were both connected to a lack of trust among partners. By granting broad-sometimes unlimited-access rights to background IP, academia/TTO and SMEs feared losing exclusivity and thus their position to negotiate deals with future interested actors. This was also seen as causing them to run a risk of potential conflicts of interest with existing contracts. In the framework of PPPs, academia/TTO and SMEs suggested that industrial parties wanted them to offer technology at bargain prices. At the same time, academia/TTO and SMEs feared that not participating in a project would result in loss of visibility. Even worse, it was feared that if they did not participate, their core technology would be surpassed by alternative solutions, and interesting IP opportunities might be missed.

Academia and SME representatives are thus left with three options: (1) not to participate in PPPs; (2) to enter conditionally; or (3) to participate unconditionally. "Either they don't participate, they are too inexperienced to realize what they can lose, or they don't put background IP in the project, leave out the most 'critical' background IP, or find a way to get around strict clauses in the contract," one TTO interviewee stated.

Industry interviewees indicated that background IP was the most contentious part of PPP negotiations. They acknowledged the difficulties for SMEs to enter a PPP, but were convinced that there are creative ways to guarantee success. Industry perceived TTOs as tough negotiators in IP discussions. One industry interviewee stated that "for industry's know-how, the academia need to give some of their proprietary knowledge in return," whereby he means that if academics want to gain insight into industry's knowhow by participating in the partnerships, they need to give something in return, such as access to relevant background IP for research use and the foreground IP (the IP rights generated by the partners within the framework of the project) generated by the project.

Unsurprisingly, all interviewees emphasized a desperate need for good PPP agreements with clear definitions. The majority of interviewees claimed that "good communication, especially related to IP issues, results in good collaboration." Academic, TTO, and SME interviewees stated that being alert, but flexible, is important when dealing with industry partners. One interviewee representing industry noted that academic/TTO partners are often too demanding when it comes to IP. He stated that the commercial value of the IP is often overestimated by the TTO, and that they often do not acknowledge the risks for pharmaceutical companies, which slows down the translation of academic findings to commercially marketed products. The SMEs pointed to their lack of experienced IP negotiators and the need for help during IP negotiations. An SME interviewee said that industry has better lawyers, and the negotiations are all about finding the balance of power. The majority of the industrial interviewees said that although there is a difference in cultures between partners, there is always a solution. "We are still at the beginning of the learning curve. It's always best to start from the PPP's guidelines if available," they argued.

All interviewees stated that negotiations on ownership of foreground IP does not cause as many problems. A company representative claimed that it is no goal of precompetitive research to generate IP, but if it comes to that point, it could be equally divided among the participants.

A good and clear IP framework from the start, including term sheets and general IP clauses included in the collaboration agreement, is a proposed solution for the lack of trust between the stakeholders in relation to the accompanying IP issues. Another solution is to define expectations well in advance-and probably to lower them a bit. One interviewee stated that complementarity between stakeholders increases trust. The ownership of foreground IP, or the right of first refusal-in case foreground IP is jointly owned and is licensed-poses no problems, as the stakeholders have different interests for commercialization. For example, a specific cell line is developed as a research tool in a project. Different parties will be interested in different aspects: a university may want to have access to the cell lines to test compounds or to investigate certain pathways, a biotechnology company can exploit and commercialize the cell line, and a pharmaceutical company will be interested to have access to the cell line to validate drug candidates.

A thorough screening of partners in advance was seen to be important for academic interviewees. One such interviewee said: "To generate IP, partners are better off in a bilateral agreement than in a PPP." Interviewees from the academic, biotechnology SMEs, and the pharma sector stated that such precompetitive partnerships are ideal platforms to get to know your partners. "Precompetitive research is the stage where you generate fundamental knowledge of interest to all parties; it's the stage before translating this knowledge into health products or therapies in a bilateral partnership," one interviewee explained.

\section{One Size Does Not Fit All}

The interviewees from the validation round recognized most of the motives and concerns of the experts and provided additional comments regarding the IP 
framework. Apart from one precompetitive PPP, the PPPs have a flexible IP framework where different stakeholder groups can negotiate the terms. "Flexibility of the IP framework," they stated, "is very important to come to an agreement." It is important for the different actors that they can negotiate an agreement that is aligned with the company's or institution's regulations and that creates a base for trust. "Precompetitive for some implies competitive for others, depending on the type of organization and point in time." Some precompetitive PPPs offer their help to SMEs during the negotiations, acting as a neutral IP specialist-an "honest broker," which facilitates negotiations and IP management in the interests of all parties. All managing directors stated that good communication and showing evidence of early successes can convince skeptics to participate. Managers of precompetitive PPPs acknowledged the important networking opportunity, and witnessed new collaborations resulting from these PPPs. Three managers of precompetitive PPPs stated that patent(s) (applications) are not the sole measure for the performance of the PPP. "It's the combination of short-term output and outcome in the long term," one validation interviewee said.

\section{DISCUSSION}

The pharmaceutical industry relied on the traditional risk-reward model for a very long time. ${ }^{26}$ To overcome the current crisis in drug development, participation of profit- and non-profit stakeholders in more dynamic collaborative $R \& D$ models might be instrumental.

Precompetitive PPPs should enhance basic knowledge, pooling of research data, and development of technology platforms. The first results are expected in the near future. Depending on the point in time and the organizational structure, the definition of "precompetitive" might differ. There is a grey zone between precompetitive and competitive research. Many precompetitive PPPs go beyond defining a hypothesis and include target identification and validation in the projects. ${ }^{24}$ On the other hand, some PD PPPs are present earlier in the drug development process and start their work with initial compound testing. ${ }^{38}$ Somewhere in between - and often overlapping - are POC PPPs. These groups increase the value of compounds, making them more attractive to pharmaceutical companies for further investment and entrance into expensive clinical trials. ${ }^{39}$ In this way, POC PPPs have a vital role in filling up the grey zone and bridging the so-called "valley of death" $11,40,41$ (i.e., the situation where risky projects are abandoned because of lack of funds required during extended time periods, rather than because of negative research outcomes).
R\&D PPPs are knowledge-based relations; hence, the management of IP rights is of critical importance. There was little consensus among the interviewees on how the IP management should be optimally organized to preserve the interests of all parties. In regard to foreground IP, interviewees had only a few concerns. If complementarity is obtained and the project leads to foreground IP, negotiations on the exploitation of the research results may not pose many problems, as different partners have different objectives and thus claim rights in different fields of applications. However, the foreground IP and the background IP are often interlinked, which then, of course, requires access rights to the background IP. It was exactly the extreme reach-through access rights to background IP that caused tensions and suspicion, according to the interviewees. Notwithstanding the abundance of precompetitive PPPs, their impact and performance can be at stake when there is a lack of trust among the stakeholders, which lack may find its origin in the IP hurdles-especially the access to background IP and information sharing.

Through their hybrid structure, PPPs are subject to unbalanced power relations between academia, SMEs, and industry. ${ }^{42}$ For academia, besides publishing, researchers are stimulated by the prospect of commercially valorizing research results, and hence, being remunerated with extra research funding; and TTOs, linked to academia, support the set-up of spin-out companies and patent filing. This changing role of academia toward more entrepreneurial activities has been discussed extensively ${ }^{43}$ and often creates tensions with industrial partners. For biotechnology SMEs developing technology platforms and research tools, patents are at the core of their business portfolios. Biopharmaceutical companies become competitors the moment a target compound is identified;

\footnotetext{
${ }^{38}$ www.mmv.org/research-development/r-d-process

${ }^{39} \mathrm{http} / / / \mathrm{lrd} . k u l e u v e n . b e / \mathrm{en} / \mathrm{tc} / \mathrm{cd} 3-1 / \mathrm{cd} 3$-discovery-of-innovativemedicines, 2011

${ }^{40}$ Gulbranson CA, Audretsch DB. Proof of concept centers: accelerating the commercialization of university innovation. J Technol Transfer 2008;33:249-258.

${ }^{41}$ Rai AK, Reichman JH, Uhlir PF, Crossman C. Pathways across the valley of death: novel intellectual property strategies for accelerated drug discovery. In: Van Overwalle G, editor. Gene Patents and Collaborative Licensing Models. Patent Pools, Clearinghouses, Open Source Models and Liability Regimes. New York: Cambridge University Press, 2009, pp 247-288.

${ }^{42}$ Ciccone DK. Arguing for a centralized coordination solution to the public-private partnership explosion in global health. Global Health Promotion 2010;17(48).

${ }^{43}$ Van Looy B, Landoni P, Callaert J, van Pottelsberghe B, Sapsalis E, Debackere K. Entrepreneurial effectiveness of European universities: an empirical assessment of antecedents and trade-offs. Research Policy 2011;40:553-564.
} 
facilitating tools are precompetitive research. Clearly, both academia and SMEs wished to appropriate their findings; often, this background IP was seen as a hurdle to participation in precompetitive PPPs. For these stakeholders, it often was difficult not to give away their core technology. ${ }^{44}$

Valuation of early stage research is difficult. ${ }^{45,46} \mathrm{An}$ industry representative critiqued TTOs for often overestimating the commercial value of IP, slowing down translation of academic findings into commercially marketed products. Furthermore, this could lead to academics and pharmaceutical companies being opposed to collaboration. ${ }^{47}$ All partners have to make the due diligence exercise for themselves and for their future partners. ${ }^{7}$ This was seen as a major challenge in precompetitive PPP negotiations. Findings need to gain value with every further step in the R\&D cycle. A potential valuation disconnect between the partners is thus lying in wait. ${ }^{48}$ Industry, SMEs, and academia need to collaborate to increase the value by translating early findings into potential drug compounds. The PPP managing bodies can help overcome IP hurdles. ${ }^{49}$

\section{Networking Platform}

Precompetitive PPPs are a platform for scientists sharing thoughts and ideas, gaining more insight into scientific enigmas, and discovering breakthroughs and disruptive innovations. Industrial partners are highly interested in the scientific performance of universities as a selection criteria for future collaborations. ${ }^{43}$ On the other hand, academics fear they will miss visibility and potential collaboration opportunities if they do not participate in PPPs. ${ }^{49}$ The conclusions of the literature on this subject are supported by the views of the interviewees, who perceive precompetitive PPPs as a platform for partner scouting, networking, and selection.

In precompetitive PPPs, the partners should focus on working with the best scientists and take the opportunity to exploit further partnerships: the managers of precompetitive PPPs acknowledge the importance of doing this. While it's too early to obtain hard figures on the outcome of precompetitive PPPs, there is evidence of new collaborations among partners. Therefore, one measure of the performance of precompetitive PPPs might be the number of partnerships established afterwards (or in parallel), in combination with the outcome (for example in terms of publications and patents) of those partnerships. After having scouted for the best future partners in a precompetitive PPP, the innovative solution to the problem-and related foreground IP - can be developed in another (PPP) collaborative model. In this way, besides increasing the value of future drug development, the value of the partnership itself is increased.

The level of trust among stakeholder groups needs to be increased for precompetitive PPPs to become ef- fective networking platforms. For the PPPs to be information-sharing platforms, flexibility in the IP policy might be of key importance. ${ }^{27,50}$ The aim of precompetitive PPPs is to boost pharmaceutical innovation and to help finding answers to the increasing technological and regulatory complexity that the pharmaceutical industry faces. Results from precompetitive PPPs projects should stimulate and form the base of an open platform for further drug development. However, the open-ended nature of precompetitive PPPs introduces complexities on the level of IP rights. More specifically, to accommodate the requisite "openness," a maximum amount of information should be shared. IP frameworks should leave enough room for stakeholders to decide on a case-by-case basis ownership or access rights. Flexibility in the IP framework is thus essential to ensure success. ${ }^{27,50}$ Clearly, this is not straightforward to adopt, and it seems that there is no ideal IP framework that suits all purposes. Open source licenses, ${ }^{7,9,20,23,25,26,46}$ with IP clauses referring to full access rights to knowledge for scientific purposes (but no commercial rights), could potentially be a source of inspiration for the design of contractual clauses regarding access rights to background IP. A combination of open source-inspired clauses guiding initial knowledge exchange, with market exploitation-oriented proprietary arrangements guiding the development of foreground IP, might remedy this situation. Furthermore, once the project enters the proof-of-concept stage and can be commercially valorized, an elaborated IP framework can be negotiated and applied. This "stage gate" model for contractual terms, reflecting the open-ended start, could increase trust and clear early IP issues. In any event, to deal with trust issues and IP issues, communication and training of the different stakeholders is critical.

${ }^{44}$ Gilbert N. Universities shun Europe's drug initiative. Nature 2010;466:306-307.

${ }^{45}$ Merz JF. Intellectual Property and Product Development Public/Private Partnerships. Final Report, May 16, 2005 to the World Health Organization Commission on Intellectual Property Rights, Innovation and Public Health. 2005.

${ }^{46}$ Bereuter TL, Jerolitsch D, Heimerl P. IPR Codes and Guidelines in Europe Facilitating Collaboration of Publicly Funded Research Organizations (PROs) with Businesses (Part 1). les Nouvelles 2011; September: 226-236.

${ }^{47}$ Schmidt C. Debate re-ignites on contribution of public research to drug development. Nat Biotechnol 2011;29:469-470.

${ }^{48}$ Kotz J. Small (molecule) thinking in academia. ScienceBusiness eXchange 2011;4(22):1-4.

${ }^{49}$ Strohmeier R, Draghia-Akli R, Rys A, et al. IMI moves forward. Nat Biotechnol 2011;29:689-790.

${ }^{50}$ Saez C. Partnership to share research, keep IP rights, on neglected diseases. http://www.ip-watch.org/2011/06/01/partnershipto-share-research-keep-ip-rights-on-neglected-diseases/ 


\section{METHODS}

To investigate the precompetitive (bio)pharmaceutical R\&D PPP model, three primary data sources were used: biomedical-economic literature, PPP websites, and interviews with key informants from industry and academia (January-December 2011).

We examined publicly available information (e.g., PPPs websites, scientific databases, case studies) to develop a census of the concept of precompetitive PPPs, their mission, and strategy.

In parallel, we first conducted a semi-structured interview round with key opinion leaders in the biopharmaceutical field. The aim was to assess motives and experiences regarding participation in precompetitive PPPs, with a specific emphasis on the role of IP rights. We developed a list of 22 experts using purposive sampling. The experts represented different stakeholder groups: big pharmaceutical companies $(n=5)$ and biotechnology SMEs $(n=5)$, both representing the private sector; academic researchers $(n=6)$, university technology transfer offices (TTOs) $(n=5)$, and a European intergovernmental agency representative $(n=1)$ - the three latter categories representing the not-for-profit sector. Two academic experts that started a spin-off company also answered from a biotechnology SME point of view (thus, $n=5+2$ ). The interviewees were based in Belgium, The Netherlands, the United Kingdom (UK), and France. Two lists were presented to the interviewees: one with motives for participation in a precompetitive PPP, and a second with motives not to participate. The interviewees could also add motives. The interviewees were asked to give their five highest-priority motives. Interviews were analyzed qualitatively using NVivo followed by a cross-case analysis to identify consistent themes and patterns.

The second interview set was a validation round. The results from the first interviews were presented to experts leading a precompetitive PPP $(n=5)$, the European Federation of Pharmaceutical Industries and Association (EFPIA) $(n=1)$, and a European Commission Joint Research Center (JRC) representative $(n=1)$. This allowed us to validate the results and identify nuances of certain findings.

\section{STUDY HIGHLIGHTS}

The concept of life science R\&D precompetitive PPPs is young and requires further in-depth research. . $^{19,20,24}$ Precompetitive PPPs can help speed up the drug-development process by stimulating competitors to collaborate in the pre-discovery phase. By sharing knowledge with peers and continuously scouting for further collaboration opportunities, an innovation platform can be created.

It is important to emphasize that the motives for participation and the expectations of different stakeholder groups differ. The question of IP management will likely remain a matter of debate, ${ }^{22}$ and the success of PPPs depends on the attitude and expertise of the participants. Instead of considering precompetitive PPPs as collaborative models, wherein exclusive rights are offered at bargain prices, stakeholders need to become aware that the value of precompetitive PPPs lies in the opportunity to scout for and network with the best scientists. Collaboration will be the only way to generate valuable IP.

\section{ACKNOWLEDGMENTS}

The authors gratefully acknowledge the experts participating in the interviews for their interesting insights. We also highly appreciate the efforts of M. Poinot, Prof. Dr. M. Goldman, Dr. E. van Zimmeren, and Prof. T. Bubela for reviewing the article. The authors also thank the editors for reviewing the article and providing interesting comments.

\section{DISCLOSURE STATEMENT}

The authors declare that they have no competing financial interests.

\section{AUTHOR CONTRIBUTIONS}

Hilde Stevens: Wrote manuscript, designed research, performed research, analyzed data.

Geertrui Van Overwalle: Contributions to original manuscript, interpretation of data.

Bart Van Looy: Contributions to original manuscript, interpretation of data.

Isabelle Huys: Designed research, performed research, contributions to original manuscript. 